\title{
The Association Between Physical Activity and Obesity among School Children and Adolescents in Jeddah, Saudi Arabia
}

\author{
Heba M. Elkhodary ${ }^{1,2}$, BDS, MSc, PhD, and Deema J. Farsi ${ }^{1}$, BDS, MSc, Diplomate ABPD \\ 'Department of Pediatric Dentistry, Faculty of Dentistry, \\ King Abdulaziz University, Jeddah, Saudi Arabia \\ 2Department of Pediatric Dentistry, Al Azhar University, Cairo, Egypt
}

\section{Correspondence}

Dr. Heba M. Elkhodary

P.O. Box 17848, Jeddah 21494, Saudi Arabia

e.M: hkhodary@kau.edu.sa

Submission: 08 May 2017

Accepted: 20 June 2017

\section{Citation}

Elkhodary HM, Farsi DJ. The association between physical activity and obesity among school children and adolescents in Jeddah, Saudi Arabia. JKAU Med Sci 2017; 24 (3): 13-27. DOl: 10.4197/Med. 24.3.2

\begin{abstract}
Obesity affects children's physical and psychological well-being. In this study we investigated the associations of obesity with physical activity, socioeconomic factors, and lifestyle among Saudi children and adolescents. A stratified sample of 729 school children and 794 adolescent students was recruited. Waist circumference and body mass index were used to categorize the participants as obese and non-obese, and a structured mixed questionnaire was used to collect socioeconomic, physical activity, and lifestyle data. The results revealed that obese adolescent males (33.5\%) were significantly more common than obese adolescent females $(13.6 \%, \mathrm{P}<0.001)$. Body mass index-based and waist circumference-based obesity was significantly more common in private schools compared to public schools among school children and adolescents $(P=0.013$ and $P=0.002$, respectively). Student obesity was associated with higher parental education, especially among the school children $(P=0.006)$. Among adolescents, obesity was strongly associated with family income ( $P$ $=0.002)$ and time spent watching television $(P=0.004)$. Non-obese children and adolescents were considered subjectively more active than their obese counterparts $(P<0.001$ and $P=0.011$, respectively). In conclusion, obesity was common among school children and adolescents, and was associated with private schooling, adolescent male sex, parental education, and family income. Physical inactivity and time spent watching television were important risk factors for obesity among Saudi school children and adolescents.
\end{abstract}

\section{Keywords}

Obesity; Prevalence; Physical inactivity; School children; Adolescents 


\section{INTRODUCTION}

besity among children and adolescents affects their physical and psychological well-being ${ }^{[1]}$. Several studies have evaluated the prevalence of obesity and overweight status among Saudi children, based on local sociocultural variations and rapid urbanization patterns $s^{[2-4]}$. The results indicate that Saudi children become overweight at the approximate age of 5-9 years, and increasing prevalence are observed among adolescents ${ }^{[5]}$. Several cross-sectional studies have also highlighted alarming increases in the Saudi prevalence of obesity based on body fat percentage and body mass index $(\mathrm{BMI})^{[6-8]}$.

Environmental and lifestyle factors contribute to the worldwide obesity epidemi ${ }^{[9]}$, and Saudi Arabia has undergone rapid recent changes in living standards. This modernization has led to lifestyle changes that include decreased physical activity and an increasingly sedentary lifestyle $e^{[3,10-12]}$. These changes are likely related to increased reliance on computer technology, telecommunication, and urbanization, which are associated with noticeable health effects ${ }^{[13]}$.

The World Health Organization (WHO) has reported that $60 \%$ of the world's population is inactive and that physical inactivity is a threat to global health, based on physical activity assessments among different populations ${ }^{[14]}$. Saudi studies have also suggested that the prevalence of physical inactivity is $43.3-99.5 \%{ }^{[13]}$, and Al-Hazzaa ${ }^{[10]}$ has reported that Saudi children and adolescents perform minimal physical activity. Mahfouz et al. ${ }^{[15]}$ investigated the sex-based differences in adolescent obesity, and reported that the lack of mandatory physical activity during school activities was a significant risk factor for obesity. Al-Ghamdi ${ }^{[16]}$ also explored the association between obesity and time spent watching television among Saudi school children, and reported that replacement of physical activity with television watching was a risk factor for obesity.

There are minimal data regarding the Saudi epidemiology of physical activity, despite the fact that Saudi Arabia has undergone massive changes in the national standard of living and has an increasing prevalence of childhood obesity ${ }^{[6-8]}$. The available data regarding the Saudi prevalence of physical activity have typically been obtained in urban areas using large and randomized samples ${ }^{[10-12,17]}$, with physical activity not being a major outcome of interest ${ }^{[12,17]}$. Thus, additional data is needed to understand, prevent, and control obesity among Saudi children. The present study aimed to investigate the associations of obesity with physical activity, socioeconomic factors, and lifestyle among Saudi school children and adolescents. The null hypothesis to be tested was: physical activity and socioeconomic factors are not associated with obesity among Saudi children and adolescents.

\section{PARTICIPANTS AND METHODS}

This cross-sectional study was performed in Jeddah, Saudi Arabia, and collected data during JanuaryMay 2017. Based on previous studies, the prevalence of obesity were assumed to be $30 \%$ among school children and $23 \%$ among adolescent students ${ }^{[18]}$. The required sample size was calculated using free webbased software (OpenEpi version 2), and individuals were randomly sampled from the elementary and secondary schools in Jeddah. The 620 public and private elementary schools teach approximately 120,000 boys and 118,500 girls. Based on a required sample of 895 school children, and a male: female ratio of 1:0.97, we recruited 450 boys and 445 girls. The 320 public and private secondary schools teach approximately 50,250 male students and 48,100 female students. Based on a required sample of 751 adolescents, and a male: female ratio of 1:0.95, we recruited 380 male adolescents and 371 female adolescents.

Schools were randomly selected for the recruitment using a previously prepared numbered list and a random number generator ${ }^{[19]}$. One public elementary school and one private elementary school were selected for each sex and each of the four main regions in Jeddah (East, South, West, and North), in order to obtain the required number of school children. For each school, two Grade 3 classes (7-10 years old) were randomly selected, and a substitute school was randomly selected if a previously selected school only had one Grade 3 class. The same procedure was performed to recruit the secondary school students (Grade 11, 15-19 years old).

The study's protocol (\#028-16) was approved by the Ethical Committee of King Abdulaziz University, Faculty of Dentistry (KAUFD), the Ministry of Education in Jeddah, and each school's principal. Students were instructed to bring a consent form home to their parents, and only students who returned signed 
consent forms were included in the evaluations. All school staff and included students received an explanation of the study before we performed the examination and measurements procedures.

\section{Sociodemographic and Physical Activity Data}

A structured questionnaire was used to gather the participants' data. The structured questionnaire was reviewed by three experts to review the questionnaire items, evaluate the correspondence between its parts and to comment on how the questions were relevant to the study. The experts rated each question and these rates were analyzed statistically to calculate the validity of questionnaire. The analysis revealed a $97.6 \%$ agreement about the questionnaire parts. The questionnaires were distributed during the first school visit, were completed at home by the parents, and were collected during the second visit.

The first part of the questionnaire collected demographic and socioeconomic data. Parents were asked to provide their name, age, sex, nationality, profession, and education level, as well as their child's school name and grade. Parental education was categorized as less than secondary school, secondary school, university, and post-graduate studies. The second part of the questionnaire included closedended questions regarding frequencies of physical activity (e.g., playing sports or walking instead of motorized transportation) and time spent watching television or playing video games. In addition, the parents were asked to provide their subjective assessment of whether or not their children were physically active.

\section{Anthropometric Measurements}

The research team was adequately trained to evaluate each participant's height, weight, and waist circumference (WC). A calibration exercise was performed for the height and WC measurements, which evaluated the intra-examiner reliability where 10 patients who attended KAUFD clinics were tested before and after a one-week interval (Kappa score 0.87 ) and inter-examiner reliability where 20 patients who attended KAUFD clinics (Kappa score 0.79). Disagreements in any measurements were resolved by re-taking the measurements until consensus was reached.
The anthropometric measurements were taken twice for each participant, and the average value was used for the analysis. Waist circumference was obtained using a regular measuring tape at the superior iliac crest while standing and during minimal breathing. Height was recorded using a commercial non-elastic measuring tape while the participant stood without shoes and with straight shoulders, freely hanging arms, and looking straight forward. The tape was used to measure the distance between the floor and a point that was marked on the wall at the highest point of the participant's head. Weight was measured using an electronic weight scale while the participants were wearing minimal clothing and no shoes ${ }^{[20,21]}$.

\section{Statistical Analysis}

All analyses were performed using IBM SPSS Statistics for Windows, Version 23 (IBM Corp., Armonk, NY USA). Data were reported as numbers and percentages. The associations of WC-based and BMI-based obesity with the participants' characteristics were evaluated in each age group using the chi-square test with Bonferroni multiple comparison correction. All P-values were twosided, and differences were considered statistically significant at $\mathrm{P}$-values of $<0.05$.

\section{RESULTS}

The participants' sociodemographic characteristics are shown in Table 1. The students included 729 children (7-10 years old, $46.2 \%$ female and $53.8 \%$ male) and 794 adolescents (15-19 years old, $51.9 \%$ female and $48.1 \%$ male). Similar proportions of the participants were enrolled in private and public schools (children: $50.3 \%$ vs. $49.7 \%$, adolescents: $50.6 \%$ vs. $49.4 \%$, respectively), and similar distributions were observed among the four districts of Jeddah. The students' fathers generally had a college degree (children: $52.7 \%$, adolescents: $42.8 \%$ ), with mothers of school children most commonly having graduated from high school $(35.0 \%)$ and mothers of adolescents most commonly having a college degree (38.7\%). The fathers were most commonly self-employed or employed in private companies (children: 32.8\%, adolescents: 36.1\%), while mothers were generally unemployed (children: $72.7 \%$, adolescents: $72.5 \%$ ). Based on BMI, $18.0 \%$ of the children and $16.0 \%$ of the adolescents were overweight, while $18.2 \%$ of children and $23.2 \%$ of adolescents were obese. Based on WC, $17.7 \%$ of the children and $18.8 \%$ of the adolescents were obese, while $82.3 \%$ of children and $81.2 \%$ of adolescents were non-obese. 
Table 1. Participant characteristics.

\begin{tabular}{|c|c|c|c|c|}
\hline & \multicolumn{4}{|c|}{ Age groups } \\
\hline & \multicolumn{2}{|c|}{$7-10$ years } & \multicolumn{2}{|c|}{$15-19$ years } \\
\hline & $\mathbf{n}$ & $\%$ & $\mathbf{n}$ & $\%$ \\
\hline \multicolumn{5}{|l|}{ Gender } \\
\hline Female & 337 & $46.22 \%$ & 412 & $51.88 \%$ \\
\hline Male & 392 & $53.77 \%$ & 382 & $48.11 \%$ \\
\hline \multicolumn{5}{|l|}{ School Type } \\
\hline Private & 367 & $50.34 \%$ & 402 & $50.62 \%$ \\
\hline Public & 362 & $49.65 \%$ & 392 & $49.37 \%$ \\
\hline \multicolumn{5}{|l|}{ District } \\
\hline East & 115 & $15.77 \%$ & 187 & $23.55 \%$ \\
\hline North & 229 & $31.41 \%$ & 213 & $26.82 \%$ \\
\hline South & 170 & $23.31 \%$ & 192 & $24.18 \%$ \\
\hline West & 215 & $29.49 \%$ & 202 & $25.44 \%$ \\
\hline \multicolumn{5}{|l|}{ Mother Occupation } \\
\hline Self-Employed & 20 & $2.74 \%$ & 43 & $5.41 \%$ \\
\hline Government Employee & 116 & $15.91 \%$ & 145 & $18.26 \%$ \\
\hline Privately Employed & 51 & $6.99 \%$ & 18 & $2.26 \%$ \\
\hline Unemployed & 530 & $72.70 \%$ & 576 & $72.54 \%$ \\
\hline Other & 12 & $1.64 \%$ & 12 & $1.51 \%$ \\
\hline \multicolumn{5}{|l|}{ Father Occupation } \\
\hline Self-Employed & 164 & $22.49 \%$ & 287 & $36.14 \%$ \\
\hline Government Employee & 155 & $21.26 \%$ & 128 & $16.12 \%$ \\
\hline Privately Employed & 239 & $32.78 \%$ & 170 & $21.41 \%$ \\
\hline Soldier/Police & 75 & $10.28 \%$ & 49 & $6.17 \%$ \\
\hline Laborer & 32 & $4.38 \%$ & 19 & $2.39 \%$ \\
\hline Unemployed & 14 & $1.92 \%$ & 100 & $12.59 \%$ \\
\hline \multicolumn{5}{|l|}{ Mother Educational Level } \\
\hline$<$ High School & 101 & $13.85 \%$ & 125 & $15.74 \%$ \\
\hline High School & 255 & $34.97 \%$ & 268 & $33.75 \%$ \\
\hline College & 335 & $45.95 \%$ & 307 & $38.66 \%$ \\
\hline Postgraduate Degree & 38 & $5.21 \%$ & 94 & $11.83 \%$ \\
\hline \multicolumn{5}{|l|}{ Father Educational Level } \\
\hline$<$ High School & 75 & $10.28 \%$ & 80 & $10.07 \%$ \\
\hline High School & 189 & $25.92 \%$ & 180 & $22.67 \%$ \\
\hline College & 384 & $52.67 \%$ & 340 & $42.82 \%$ \\
\hline Postgraduate Degree & 81 & $11.11 \%$ & 194 & $24.43 \%$ \\
\hline \multicolumn{5}{|l|}{ BMI Classification } \\
\hline Underweight & 7 & $9.60 \%$ & 55 & $6.92 \%$ \\
\hline Normal weight & 458 & $62.82 \%$ & 428 & $53.90 \%$ \\
\hline Overweight & 131 & $17.96 \%$ & 127 & $15.99 \%$ \\
\hline Obese & 133 & $18.24 \%$ & 184 & $23.17 \%$ \\
\hline \multicolumn{5}{|l|}{ WC Classification } \\
\hline Non-obese & 600 & $82.30 \%$ & 645 & $81.23 \%$ \\
\hline Obese & 129 & $17.69 \%$ & 149 & $18.76 \%$ \\
\hline
\end{tabular}

The physical activity data are shown in Table 2 . Approximately three-quarters of the school children (73.9\%) and adolescents (76.5\%) played sports, with frequencies classified as 1 time/week, 2-3 times/ week, and $\geq 4$ times/week. Approximately twothirds of school children (69.3\%) and only $38 \%$ of adolescents played 2-3 times/week. Time spent watching television was classified as $1 \mathrm{hr} /$ day, $2-3 \mathrm{hr} /$ day, and $\geq 4 \mathrm{hr} /$ day. Approximately one-half (52.9\%) of school children and $36.6 \%$ of adolescents watched an average of 2-3 hr/day. High percentages of school children and adolescents did not walk to school $(94.7 \%$ and $91.9 \%$, respectively) or elsewhere $(89.4 \%$ and $84.9 \%$, respectively). The parents' subjective opinions 
The Association Between Physical Activity and Obesity among School Children and Adolescents in Jeddah, Saudi Arabia Heba M. Elkhodary and Deema J. Farsi

Table 2. Physical activity.

\begin{tabular}{|c|c|c|c|c|c|}
\hline & & \multicolumn{4}{|c|}{ Age Group } \\
\hline & & \multicolumn{2}{|c|}{ 7-10 Years } & \multicolumn{2}{|c|}{ 15-19 Years } \\
\hline & & $\mathbf{n}$ & $\%$ & $\mathbf{n}$ & $\%$ \\
\hline \multirow[t]{2}{*}{ Is your child engaged in sports? } & No & 190 & $26.06 \%$ & 186 & $23.42 \%$ \\
\hline & Yes & 538 & $73.79 \%$ & 607 & $76.44 \%$ \\
\hline \multirow[t]{4}{*}{ If yes, how many times per week? } & No & 0 & $0.00 \%$ & 181 & $22.79 \%$ \\
\hline & 1 & 93 & $12.75 \%$ & 165 & $20.78 \%$ \\
\hline & $2-3$ & 505 & $69.27 \%$ & 302 & $38.03 \%$ \\
\hline & $\geq 4$ & 131 & $17.96 \%$ & 146 & $18.38 \%$ \\
\hline \multirow{3}{*}{$\begin{array}{l}\text { How many hours per day does the child spend } \\
\text { watching TV? }\end{array}$} & 1 & 207 & $28.39 \%$ & 192 & $24.18 \%$ \\
\hline & $2-3$ & 386 & $52.94 \%$ & 290 & $36.52 \%$ \\
\hline & $\geq 4$ & 136 & $18.65 \%$ & 311 & $39.16 \%$ \\
\hline \multirow{2}{*}{$\begin{array}{l}\text { To go to school, does your child walk or use } \\
\text { transportation (car/bus)? }\end{array}$} & Transportation & 690 & $94.65 \%$ & 729 & $91.81 \%$ \\
\hline & Walk & 39 & $5.34 \%$ & 64 & $8.06 \%$ \\
\hline \multirow{2}{*}{$\begin{array}{l}\text { Other than school, does your child walk or take } \\
\text { transportation to go out? }\end{array}$} & Transportation & 652 & $89.43 \%$ & 673 & $84.76 \%$ \\
\hline & Walk & 77 & $10.56 \%$ & 120 & $15.11 \%$ \\
\hline \multirow{2}{*}{$\begin{array}{l}\text { In your opinion, is your child physically active or } \\
\text { sedentary? }\end{array}$} & Active & 679 & $93.14 \%$ & 654 & $82.36 \%$ \\
\hline & Sedentary & 50 & $6.85 \%$ & 140 & $17.63 \%$ \\
\hline
\end{tabular}

indicated that $(93.1 \%)$ of the children and $(82.4 \%)$ of the adolescents were physically active, and only (6.9\%) of children and (17.6\%) of adolescents were considered physically inactive.

Table 3 shows the participants' demographic characteristics according to age and BMI category. The proportion of obese adolescent males (33.5\%) was significantly higher than the proportion of obese adolescent females (13.6\%, $P<0.001)$. Private schooling was also associated with BMI-based obesity among children $(P=0.013)$ and adolescents $(P=0.002)$. Student obesity increased with higher parental education levels, with the strongest association observed among the school children $(P=0.006)$. Student BMIbased obesity was not significantly associated with parental occupation, although BMI-based obesity was significantly associated with family income among adolescents $(P=0.002)$. The prevalence of normalweight adolescents was highest in the "sufficient income" category (68.5\%), and was followed by the "some saving" category (58.4\%) and the "insufficient income" category (53.6\%).

Table 4 shows the participants' demographic characteristics according to age and WC category. Significant sex-based differences in the WC categories were observed among the children $(P=0.001)$ and adolescents $(P=0.04)$. The prevalence of obese females was greater among school children $(P=0.032)$, while the prevalence of obese males was greater among adolescents $(P<0.001)$. Similar to the associations with BMI-based obesity, WC-based obesity was associated with school type, parental occupation, and family income.

Table 5 shows the physical activity data according to age and BMI category. In both age groups, BMIbased obesity was not significantly associated with playing sports, frequency of playing sports, or walking instead of using motorized transportation. However, time spent watching television was associated with adolescent obesity, with $45.1 \%$ of adolescent students watching $\geq 4 \mathrm{hr} /$ day $(P=0.004)$. The parents' subjective assessment of physical activity was significantly associated with obesity, with greater physical activity reported for normal-weight children $(P=0.011)$ and normal-weight adolescents $(P<0.001)$, compared to their obese counterparts.

Table 6 shows the physical activity data according to age and WC category. Similar to the BMI-based association, time spent watching television was significantly associated with WC-based obesity among 


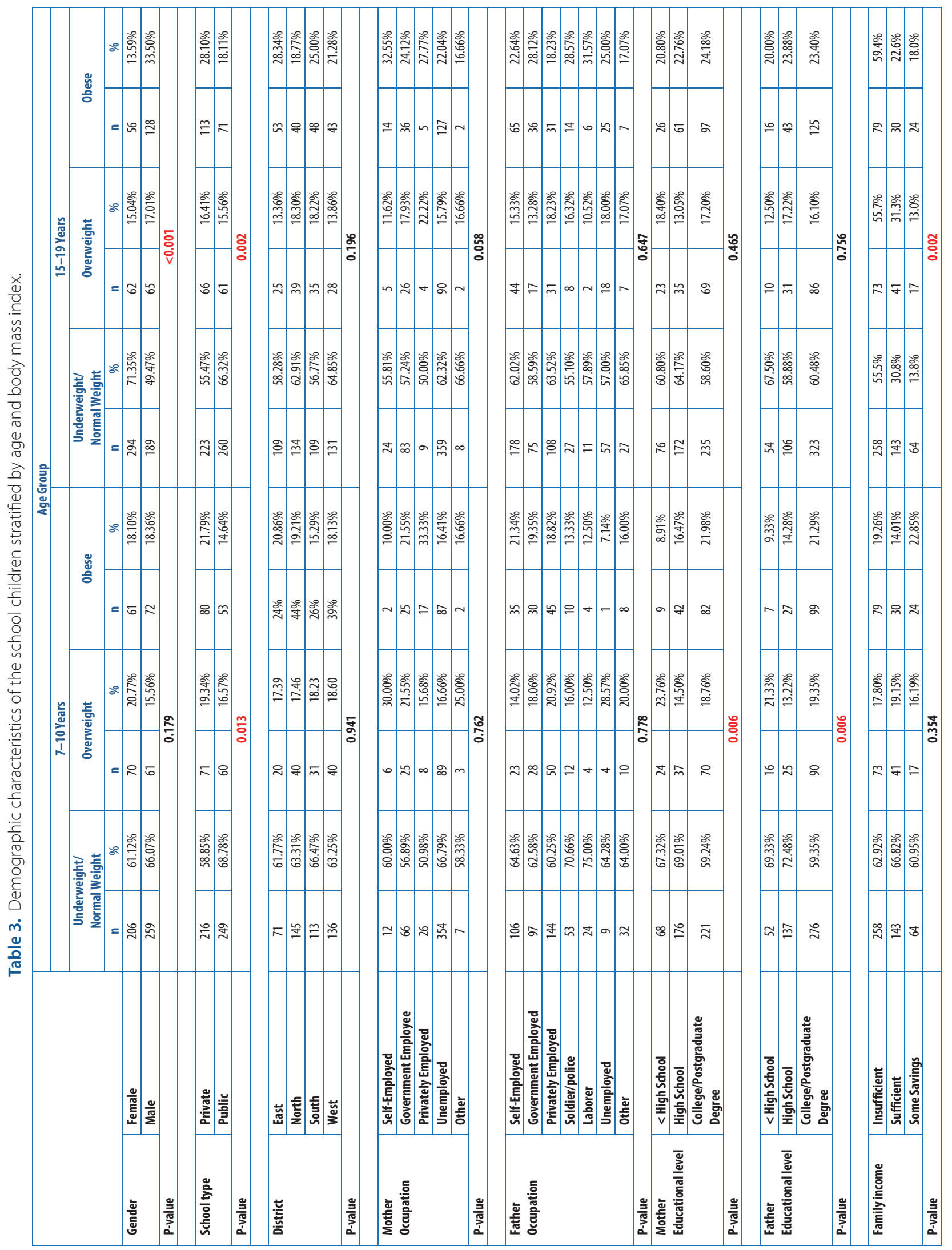




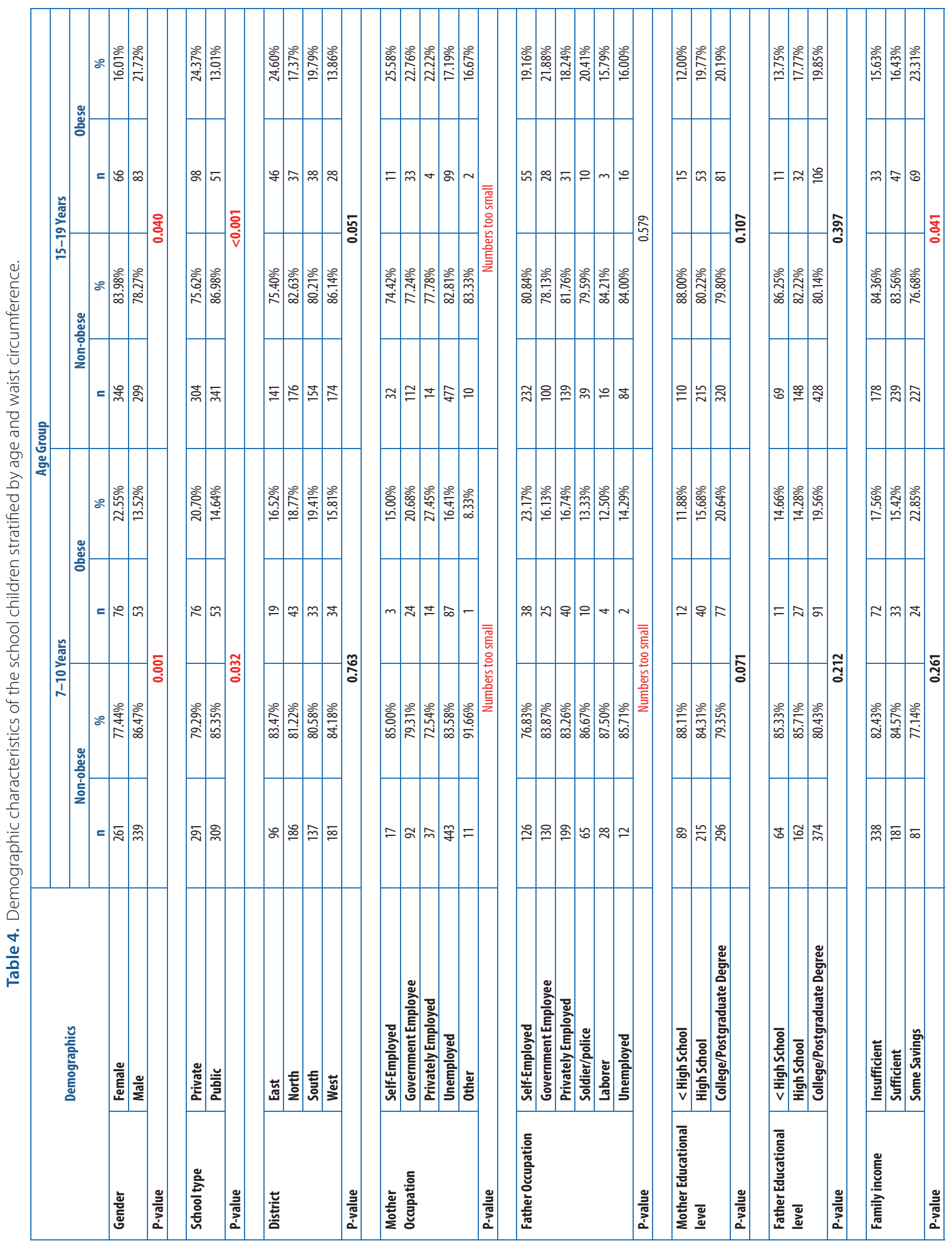




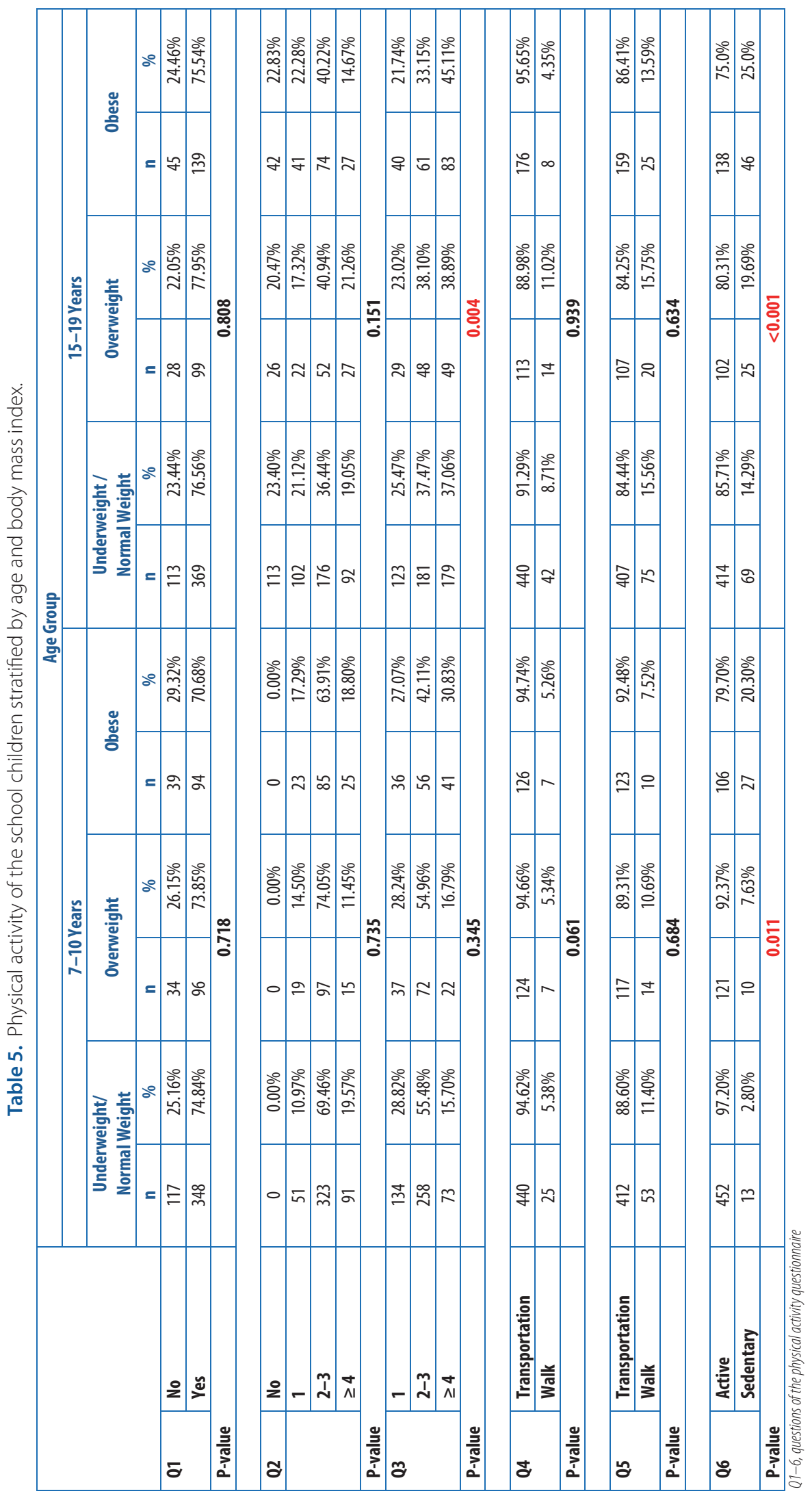




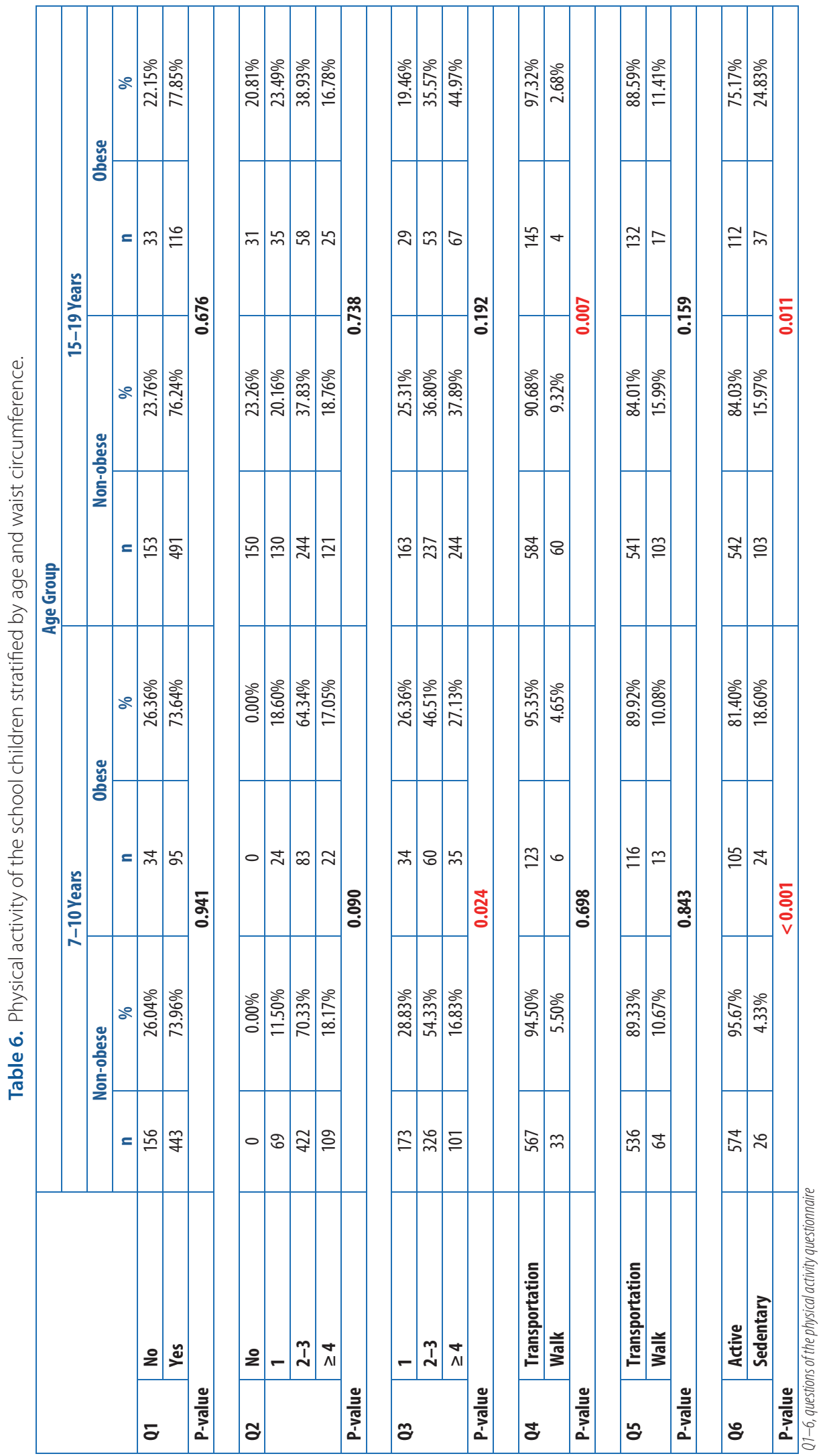


the children $(P=0.024)$. Furthermore, the parents' subjective assessment of physical activity was also significantly associated with WC-based obesity, with greater physical activity reported for normal-weight children $(P<0.001)$ and normal-weight adolescents $(P$ $=0.011)$, compared to their obese counterparts.

\section{DISCUSSION}

Several governmental reports have confirmed high rates of overweight status and obesity among Saudi children and adolescents, and previous reports have linked sedentary lifestyle to obesity ${ }^{[10,18,22,23]}$. Therefore, the present study aimed to evaluate the associations of obesity with physical activity, socioeconomic factors, and education among children and adolescents in Jeddah. School children and adolescent students were selected for the present study because they can perform various types of physical activity in school and during their daily lives ${ }^{[24]}$. The null hypothesis that physical activity and socioeconomic factors are not associated with obesity among Saudi children and adolescents is rejected.

The study revealed non-significant differences in the BMI values for the male and female children, although female children were significantly more likely to have WC-based obesity, compared to male children. This discrepancy may be related to the different measurements for $\mathrm{BMI}$ and WC, as WC considers fat accumulation around the lower trunk, while BMI measures body mass regardless of the ratio of muscle to fat. Another explanation might be that boys are usually more active and more likely to participate in physical activity and sports, compared to girls. Similarly, Farsi et al. ${ }^{[25]}$ found that female children were more obese, compared to male children, based on WC measurements but not BMI. However, 2005 data from the health survey for England revealed a lower incidence of obesity among girls who were $\leq 11$ years old, compared to boys ${ }^{[26]}$.

In the present study, adolescent males were significantly more obese based on BMI and WC, compared to adolescent females. Similarly, Abalkhail ${ }^{[6]}$ studied overweight and obesity trends among schoolchildren and adolescents in Jeddah using data from 1994 and 2000, and found that 14-16-year-old girls were less obese, compared to their male counterparts. In addition, Farsi and Elkhodary ${ }^{[27]}$ studied the prevalence of overweight status and obesity among adolescents, and reported that males were more likely to be obese (vs. females), because they more frequently went out with their friends and ate junk food. Moreover, similar findings have been reported among adolescents from Saudi Arabia ${ }^{[2,29]}$, Britain ${ }^{[30]}$, and the United States (US) [31]. It is possible that these differences are related to greater consumption of sugar and sugar-sweetened carbonated beverages among male adolescents, compared to female adolescents ${ }^{[29]}$. Nevertheless, other Saudi studies revealed that obesity was more prevalent among female adolescents, compared to male adolescents ${ }^{[4,32]}$. Al-Hazzaa et al. ${ }^{[33]}$ have reported that physical activity was a weak risk factor for obesity among females, while Collison et al. ${ }^{[29]}$ have reported that all Saudi children are increasingly gravitating towards sugar-rich foods and unhealthy dietary choices. Thus, less physical activity and greater sugar consumption among Saudi adolescents may explain their relatively high prevalence of obesity, compared to school children.

Interestingly, the prevalence of BMI-based and WC-based obesity among children and adolescents was significantly higher in private schools, compared to public schools. Similar results have been reported by Pattanaik et al. ${ }^{[34]}$ who observed a higher prevalence of obesity/overweight status among school children in private Indian schools. Furthermore, Patnaik et al. ${ }^{[35]}$ and Jagadesan et al. ${ }^{[36]}$ have reported a higher proportion of overweight status/obesity in other private schools. The service of obesity-promoting foods in private schools might play a major role in this association ${ }^{[37]}$. Furthermore, children who attend public school more frequently come from lower income families, who might not be able to afford school food or to provide large meals at home. In contrast, children who attend private schools are more likely to have money to buy snacks and can afford larger meals. Other studies ${ }^{[38,39]}$ have attributed the differences in obesity prevalence between public and private schools to the students walking to school and being driven to school, respectively.

Among the students in the present study, BMIbased obesity was associated with higher parental education, although this association was more significant among school children. In contrast, findings from an American health and nutrition examination survey (2005-2008) revealed that children and adolescents whose fathers had low education levels were more likely to be obese, compared to families in which the father had a college degree ${ }^{[40]}$. Nevertheless, Al Alwan et al. ${ }^{[41]}$ also found a significant association 
between obesity/overweight status among mothers with higher levels of education. Moreover, Gnavi et al. ${ }^{[42]}$ and Anderson et al. ${ }^{[43]}$ have reported associations between childhood obesity and the mother working, which may be related to the children skipping meals and selecting unhealthy snacks because they spend large amounts of time away from home ${ }^{[42,43]}$. Because educated Saudi women frequently spend most of their time at work or engaged in social activities, rather than spending time with their children, a caregiver or maid typically spends the most time with the children and has the greatest influence on their diet and time spent watching television. However, in contrast with our findings, reports from the United States (US) ${ }^{[44]}$ and United Kingdom (UK) ${ }^{[45]}$ have revealed that obesity was more prevalent among children from parents with low education levels. Moraeus et al. ${ }^{[46]}$ also found a higher prevalence of overweight status and obesity among children whose parents had low educational levels, as these children were less likely to play organized sports and more likely to be physically inactive.

Among adolescents, BMI-based obesity was associated with family income in the present study, as normal-weight adolescents were most common in the "sufficient income" group, compared to the "some saving" and "insufficient income" group, while obesity was most common among high-income families. Similarly, Alam ${ }^{[2]}$ observed a high obesity rate in the affluent districts of Riyadh, with anecdotal evidence of inactive children residing in fancy houses. Moreover, Amin et al. ${ }^{[47]}$ studied overweight and obese male students (10-14 years old) in the eastern region of Saudi Arabia, and reported a significant relationship between high socio-economic standards and obesity. It is possible that families with low incomes try to save money by preparing their meals at home and only eating once or twice per day, while more affluent families can afford more meals/snacks per day, home delivery services, and eating in restaurants ${ }^{[48]}$.

In the present study, playing sports, the frequency of playing sports, and walking to school/other destinations were not significantly associated with obesity among the children and adolescents. However, normal-weight students (based on BMI or WC) were more likely to be considered physically active by their parents, compared to overweight or obese students. Mahfouz et al. ${ }^{[15]}$ and Al-Hazzaa et al. ${ }^{[49]}$ have also evaluated the associations of physical activity and other lifestyle factors with obesity, and reported positive correlations between obesity and physical inactivity. Furthermore, Saudi studies have reported that a lack of exercise was a significant risk factor for obesity among adolescents from southwestern Saudi Arabia $^{[34]}$, and that low physical activity was associated with obesity among Saudi adolescents $s^{[3]}$.

Time spent watching television is an important factor in the development of childhood obesity ${ }^{[50]}$. In the present study, watching television for $\geq 4 \mathrm{hr} /$ day was significantly associated with BMI-based obesity, and similar findings have been reported by other researchers ${ }^{[16,51]}$. It is possible that watching television for prolonged periods reduces the amount of physical activity and/or causes children to consume more or different foods. Nevertheless, other studies have revealed weak $^{[52]}$ or negative associations between obesity and watching television among children and adolescents ${ }^{[49,53]}$. However, weak or negative associations might be related to relatively short followups or different age groups being examined in the different studies.

The present study has several strengths. First, we recruited a large number of students from various geographical areas in Jeddah. Second, we considered both $\mathrm{BMI}$ and WC data to categorize the participants as obese or non-obese. Third, a reliable and valid closedended questionnaire was used to obtain data regarding obesity, socioeconomic characteristics, lifestyle, and physical activity. Nevertheless, the present study also has several limitations. First, the cross-sectional design precludes any commentary regarding the causality of the associations that we observed. Second, the questionnaire relied on subjective parental assessments for some variables, which could have been inaccurate, although this format is common in similar studies. Third, we only evaluated children from Jeddah, and it is possible that our findings are not representative of other regions of Saudi Arabia.

\section{Conclusion}

In conclusion, obesity was common among school children and adolescents, and was associated with private schooling, adolescent male sex, parental education level, and family income. Physical inactivity and time spent watching television are important risk factors for obesity among school children and adolescents. It is therefore recommended for authorities developing prevention programs to implement healthy lifestyle education programs with great focus on increasing physical education hours and on educating 
The Association Between Physical Activity and Obesity among School Children and Adolescents in Jeddah, Saudi Arabia Heba M. Elkhodary and Deema J. Farsi

children and parents to the hazards of overweight/ obesity. In addition, more future programs should be directed to parents to encourage their positive role in reducing the time their children spend watching TV and their engagement in physical activities.

\section{Future Research}

Further analytical studies should be encouraged to study other possible risk factors in other provinces in Saudi Arabia to expand our research on a national scale and to encourage cross-national initiatives to establish monitoring and preventing programs.

\section{Acknowledgments}

This project was funded by the Deanship of Scientific Research, King Abdulaziz University, Jeddah (38-165523). The authors thank the Deanship of Scientific Research for providing technical and financial support. The authors thank Professor Inas Elattar for performing the statistical analysis, as well as Dr. Leena Merdad, Dr. Amal Swelem, and Professor Najat Farsi for their continuous support.

\section{Conflict of Interest}

The authors have no conflict of interest.

\section{Disclosure}

None of the authors received any type of commercial support either in forms of compensation or financial for this study. They have no financial interest in any of the products or devices, or drugs mentioned in this article.

\section{Ethical Approval}

Obtained.

\section{REFERENCES}

[1] Reilly JJ. Descriptive epidemiology and health consequences of childhood obesity. Best Pract Res Clin Endocrinol Metab 2005; 19(3): 327-341.

[2] Alam AA. Obesity among female school children in North West Riyadh in relation to affluent lifestyle. Saudi Med J 2008; 29(8): 1139-1144.

[3]1 Al-Rukban MO. Obesity among Saudi male adolescents in Riyadh, Saudi Arabia. Saudi Med J 2003; 24(1): 27-33.

[4] El-Hazmi MA, Warsy AS. The prevalence of obesity and overweight in 1-18-year-old Saudi children. Ann Saudi Med 2002; 22(5-6): 303-307.
[5] Rudolf MC, Sahota P, Barth JH, Walker J. Increasing prevalence of obesity in primary school children: cohort study. BMJ 2001; 322(7294): 1094-1095.

[6] Abalkhail B. Overweight and obesity among Saudi Arabian children and adolescents between 1994 and 2000. East Mediterr Health J 2002; 8(4-5): 470-479.

[7] Al-Hazzaa HM. Rising trends in BMI of Saudi adolescents: evidence from three national cross-sectional studies. Asia Pac J Clin Nutr 2007; 16(3): 462-466.

[8] Al-Hazzaa HM. Prevalence and trends in obesity among school boys in Central Saudi Arabia between 1988 and 2005. Saudi Med J 2007; 28(10): 1569-1574.

[9] Kant AK, Graubard BI. Secular trends in patterns of selfreported food consumption of adult Americans: NHANES 1971-1975 to NHANES 1999-2002. Am J Clin Nutr 2006; 84(5): 1215-1223.

[10] Al-Hazzaa HM. Physical activity, fitness and fatness among Saudi children and adolescents: implications for cardiovascular health. Saudi Med J 2002; 23(2): 144-150.

[11] Al-Rafaee S, Al-Hazzaa HM. Physical activity profile of adult males in Riyadh City. Saudi Med J 2001; 22(9): 784-789.

[12] Al-Shahri MZ, Al-Almaei SM. Promotion of physical exercise by primary health care physicians in Riyadh city. Saudi Med J 1998; 19(1): 67-69.

[13] Al-Hazzaa HM. Prevalence of physical inactivity in Saudi Arabia: a brief review. East Mediterr Health J 2004; 10(4-5): 663-670.

[14] World Health Organization. Annual Global Move for Health Initiative, a Concept Paper. Geneva, Switzerland; WHO, 2003. 1-12

[15] Mahfouz AA, Shatoor AS, Khan MY, Daffalla AA, Mostafa OA, Hassanein MA. Nutrition, physical activity, and gender risks for adolescent obesity in Southwestern Saudi Arabia. Saudi J Gastroenterol 2011; 17(5): 318-322.

[16] Al-Ghamdi SH. The association between watching television and obesity in children of school-age in Saudi Arabia. J Family Community Med 2013; 20(2): 83-89.

[17] Taha AZ, Bella H. Heart disease risk factors: prevalence and knowledge in a primary care setting, Saudi Arabia. East Mediterr Health J 1998; 4(2): 293-300.

[18] Al-Dossary SS, Sarkis PE, Hassan A, Ezz El Regal M, Fouda AE. Obesity in Saudi children: a dangerous reality. East Mediterr Health J 2010; 16(9): 1003-1008.

[19] Bouchard GA, Brasili DS, Carlson DA, Varadharajan A. Random number generator. Google Patents. 2005

[20] Janssen I, Katzmarzyk PT, Ross R. Waist circumference and not body mass index explains obesity-related health risk. Am J Clin Nutr 2004; 79(3): 379-384.

[21] Li C, Ford ES, Mokdad AH, Cook S. Recent trends in waist circumference and waist-height ratio among US children and adolescents. Pediatrics 2006; 118(5): e1390-e1398.

[22] Al-Saeed WY, Al-Dawood KM, Bukhari IA, Bahnassy A. Prevalence and socioeconomic risk factors of obesity 
among urban female students in Al Khobar city, Eastern Saudi Arabia, 2003. Obes Rev 2007; 8(2): 93-99.

[23] Sabra AA, Al-Sofii SM. Childhood obesity in primary health care centers in Al-Khobar city, Saudi Arabia: Prevalence and associated risk factors. Bull High Inst Public Health 2006; 36(1): 65-82.

[24] Baranowski T, Mendlein J, Resnicow K, Frank E, WeberCullen K, Baranowski JC. Physical activity and nutrition in children and youth: an overview of obesity prevention. Prev Med 2000; 31(2): S1-S10.

[25] Farsi DJ, Elkhodary HM, Merdad LA, Farsi NM, Alaki SM, Alamoudi NM, Bakhaidar HA, Alolayyan MA. Prevalence of obesity in elementary school children and its association with dental caries. Saudi Med J 2016; 37(12): 1387-1394.

[26] Jotangia D, Moody A, Stamatakis E, Wardle, E. Obesity among Children under 11. London UK: Nat Cen 2005. Available: https://www.bipsolutions.com/docstore/pdf/10271.pdf

[27] Farsi DJ, Elkhodary HM. The prevalence of overweight/ obesity in high school adolescents in Jeddah and the association of obesity association with dental caries. Ann Saudi Med 2017; 37(2): 114-121.

[28] Bello LL, Al-Hammad N. Pattern of fluid consumption in a sample of Saudi Arabian adolescents aged 12-13 years. Int J Paediatr Dent 2006; 16(3): 168-173.

[29] Collison KS, Zaidi MZ, Subhani SN, Al-Rubeaan K, Shoukri M, Al-Mohanna FA. Sugar-sweetened carbonated beverage consumption correlates with BMI, waist circumference, and poor dietary choices in school children. BMC Public Health 2010; 10: 234.

[30] He FJ, Marrero NM, MacGregor GA. Salt intake is related to soft drink consumption in children and adolescents. Hypertension 2008; 51(3): 629-634.

[31] French SA, Lin BH, Guthrie JF. National trends in soft drink consumption among children and adolescents age 6 to 17 years: prevalence, amounts, and sources, 1977/1978 to 1994/1998. J Am Diet Assoc 2003; 103(10): 1326-1331.

[32] Farghaly NF, Ghazali BM, Al-Wabel HM, Sadek AA, Abbag FI. Life style and nutrition and their impact on health of Saudi school students in Abha, Southwestern region of Saudi Arabia. Saudi Med J 2007; 28(3): 415-421.

[33] Al-Hazzaa HM, Abahussain NA, Al-Sobayel HI, Qahwaji DM, Musaiger AO. Physical activity, sedentary behaviors and dietary habits among Saudi adolescents relative to age, gender and region. Int J Behav Nutr Phys Act 2011; 8: 140.

[34] Pattanaik S, Patnaik L, Patnaik S, Hussain M. Prevalence of overweight and obesity in a private school of Orissa, India. Internet J Epidemiol 2011; 10: 1-5.

[35] Patnaik L, Pattanaik S, Sahu T, Rao EV. Overweight and obesity among Adolescents, a comparative study between government and private schools. Indian Pediatr 2015; 52(9): 779-781.
[36] Jagadesan S, Harish R, Miranda P, Unnikrishnan R, Anjana RM, Mohan V. Prevalence of overweight and obesity among school children and adolescents in Chennai. Indian Pediatr 2014; 51(7): 544-549.

[37] Mwaikambo SA, Leyna GH, Killewo J, Simba A, Puoane T. Why are primary school children overweight and obese? A cross sectional study undertaken in Kinondoni district, Dar-es-Salaam. BMC Public Health 2015; 15: 1269.

[38] Pabayo R, Gauvin L, Barnett TA, Nikiéma B, Séguin L. Sustained active transportation is associated with a favorable body mass index trajectory across the early school years: findings from the Quebec Longitudinal Study of Child Development birth cohort. Prev Med 2010; 50 Suppl 1: S59-S64.

[39] Duncan S, Duncan EK, Fernandes RA, Buonani C, Bastos KD, Segatto AF, Codogno JS, Gomes IC, Freitas IF Jr. Modifiable risk factors for overweight and obesity in children and adolescents from São Paulo, Brazil. BMC Public Health 2011; 11: 585.

[40] Ogden CL, Lamb MM, Carroll MD, Flegal KM. Obesity and socioeconomic status in children and adolescents: United States, 2005-2008. NCHS Data Brief 2010; (51): 1-8.

[41] Al Alwan I, Al Fattani A, Longford N. The effect of parental socioeconomic class on children's body mass indices. J Clin Res Pediatr Endocrinol 2013; 5(2): 110-115.

[42] Gnavi R, Spagnoli TD, Galotto C, Pugliese E, Carta A, Cesari L. Socioeconomic status, overweight and obesity in prepuberal children: a study in an area of Northern Italy. Eur J Epidemiol 2000; 16(9): 797-803.

[43] Anderson PM, Butcher KF, Levine PB. Maternal employment and overweight children. J Health Econ 2003; 22(3): 477504.

[44] Singh GK, Siahpush M, Kogan MD. Rising social inequalities in US childhood obesity, 2003-2007. Ann Epidemiol 2010; 20(1): 40-52.

[45] Howe LD, Tilling K, Galobardes B, Smith GD, Ness AR, Lawlor DA. Socioeconomic disparities in trajectories of adiposity across childhood. Int J Pediatr Obes 2011; 6(2-2): e144-e153.

[46] Moraeus L, Lissner L, Yngve A, Poortvliet E, Al-Ansari U, Sjöberg A. Multi-level influences on childhood obesity in Sweden: societal factors, parental determinants and child's lifestyle. Int J Obes (Lond) 2012; 36(7): 969-976.

[47] Amin TT, Al-Sultan Al, Ali A. Overweight and obesity and their relation to dietary habits and socio-demographic characteristics among male primary school children in AlHassa, Kingdom of Saudi Arabia. Eur J Nutr 2008; 47(6): 310-318.

[48] Mirmiran P, Sherafat-Kazemzadeh R, Jalali-Farahani S, Azizi F. Childhood obesity in the Middle East: a review. East Mediterr Health J 2010; 16(9): 1009-1017.

[49] Al-Hazzaa HM, Abahussain NA, Al-Sobayel HI, Qahwaji DM, Musaiger AO. Lifestyle factors associated with overweight 
The Association Between Physical Activity and Obesity among School Children and Adolescents in Jeddah, Saudi Arabia Heba M. Elkhodary and Deema J. Farsi

and obesity among Saudi adolescents. BMC Public Health 2012; 12: 354.

[50] Proctor MH, Moore LL, Gao D, Cupples LA, Bradlee ML, Hood MY, Ellison RC. Television viewing and change in body fat from preschool to early adolescence: The Framingham Children's Study. Int J Obes Relat Metab Disord 2003; 27(7): 827-833.

[51] Gomez LF, Parra DC, Lobelo F, Samper B, Moreno J, Jacoby E, Lucumi DI, Matsudo S, Borda C. Television viewing and its association with overweight in Colombian children: results from the 2005 National Nutrition Survey: A cross sectional study. Int J Behav Nutr Phys Act 2007; 4: 41.

[52] Burke V, Beilin LJ, Durkin K, Stritzke WG, Houghton S, Cameron CA. Television, computer use, physical activity, diet and fatness in Australian adolescents. Int J Pediatr Obes 2006; 1(4): 248-255.

[53] Janssen I, Katzmarzyk PT, Boyce WF, King MA, Pickett W. Overweight and obesity in Canadian adolescents and their associations with dietary habits and physical activity patterns. J Adolesc Health 2004; 35(5): 360-367. 
المملاقة بين النشاط البيةني والبدانة بين أطفال المدارس والمراهقين في جدة،

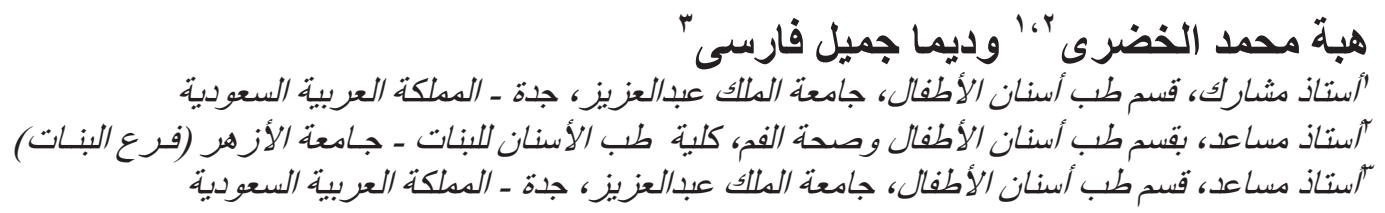

المستخُص. تؤثر السمنة على سلامة الطفل البدنية والنفسية لذا بحثت هذه الدراسة العلاقة بين السمنة والنشاط البدني

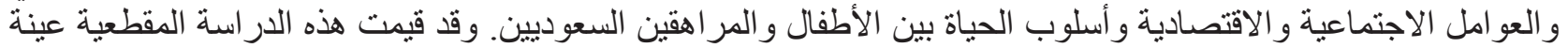

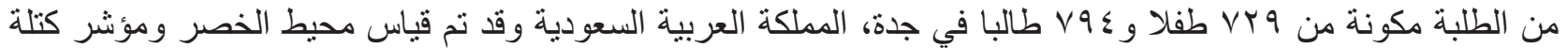

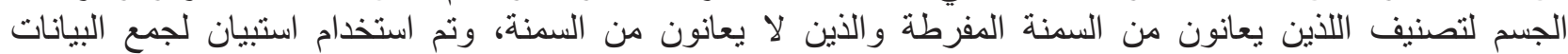

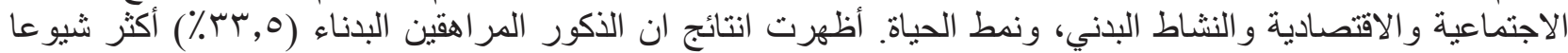

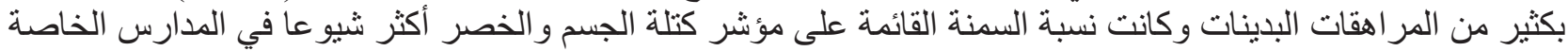

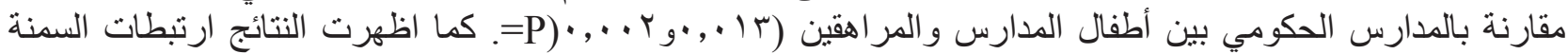

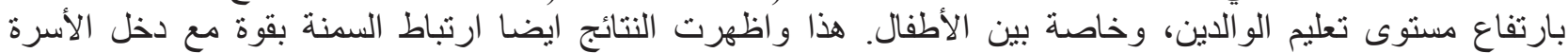

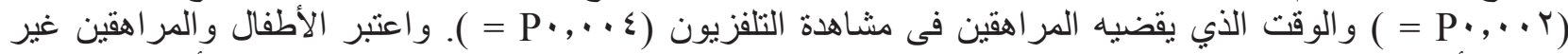

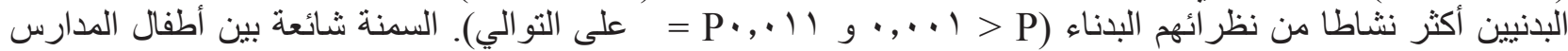

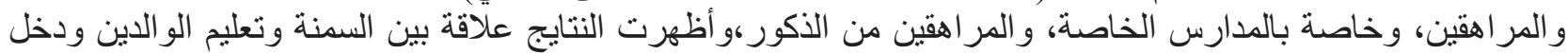

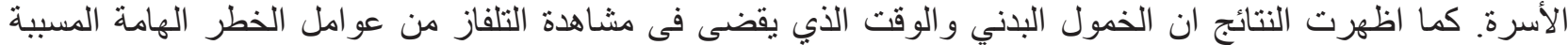
للبدانة بين المر اقين و أطفال المدارس الستر السعودية. 